\title{
Standardised Predictive Linear Models of Managerial Processes and the Sustainability of Graduate Programmes (SGPs) in Universities: A Case Study
}

\author{
Valentine Joseph Owan ${ }^{1 *}$ (D), Oni Enene Offu ${ }^{1}$ (])
}

${ }^{1}$ Department of Educational Management, University of Calabar, Calabar, NIGERIA

*Corresponding Author: owanvalentine@gmail.com

Citation: Owan, V. J., \& Offu, O. E. (2021). Standardised Predictive Linear Models of Managerial Processes and the Sustainability of Graduate Programmes (SGPs) in Universities: A Case Study. Contemporary Mathematics and Science Education, 2(1), ep21006. https://doi.org/10.30935/conmaths/9681

\begin{abstract}
The exploration of the literature indicated that much studies abound in related areas. Much seems yet to be known about the nature of the relationship that exists between managerial variables and the sustainability of graduate programmes. To bridge this gap, we utilized a standardised multiple regression approach to build up linear models that examine three managerial processes (strategic planning, staff and information/communication management) and how they affect three proxies of the sustainability of graduate programmes (availability of funds and facilities, as well as supervision) respectively and cumulatively. Quantitative data were obtained from an entire population of 149 managers (Head of Departments and Deans) in the University of Calabar, Calabar, Nigeria using a questionnaire. Findings emerged, among others, a significant relationship between each of the managerial processes to the sustainability of graduate programmes generally and particularly in terms of availability of funds, facilities and supervision; the three predictor variables partially and jointly accounted for significant proportions in the sustainability of graduate programmes generally and specifically in terms of the various dimensions. Based on this evidence, one general and three partial predictive linear equations, as well as models were derived, while relevant action-based implications for effective management and practice were discussed.
\end{abstract}

Keywords: graduate programmes, linear models, managerial processes, predictive models, standardized regression, sustainability, universities

Received: 18 Oct. 2020 Accepted: 24 Nov. 2020

\section{INTRODUCTION}

The idea of sustainable development has recently become an essential issue for educational stakeholders. It is the tradition of upholding processes of productivity continuously through the rational use of resources to achieve objectives. It deals with the ability to attract, satisfy and retain students, staff as well as make available relevant material resources that are capable of keeping an educational system on. It paves the way for continuity and works towards preventing education institutions from experiencing a collapse. Sustainability addresses our immediate needs without undermining future generations ' ability to fulfil their own needs. (World Commission on Economic Development, 1987). To Garba (2010), sustainability is the continued existence of a firm. sustainability is more by the problems it addresses rather than the disciplines it employs (Clark, 2012). According to Ayeni (2008), the continuity or sustainability of schools entails constant school enrolment, maintenance of staff and effective teaching. Any obstruction in any of these areas means that the school is gradually ending or breaking down.
From the foregoing, it implies that sustainability of graduate programmes (SGPs) refers to all the efforts made by those concerned in ensuring that there is continuity, functionality and smooth running of graduate programmes in universities. A graduate programme can be said to be sustainable if it provides beyond reasonable doubts, evidence that it possesses the required quality of instructors, students, adequate facilities such as libraries, lecture rooms, and hostels for students among others to cater for the different needs of respective courses and students. Graduate programmes in universities are programmes designed to build academic pathway after bachelor's degree programmes. Graduate programmes in institutions that lack adequate funds, poorly motivated staff, and poor infrastructural provisions are not likely to be sustained. This is because the efficiency of widely available human and material capital can dictate to what degree the viability of academic programmes can be accomplished (Pisca, 2016).

The SGPs seems to have received little or no attention in developed nations of the world perhaps due to the level of satisfaction with the quality of services rendered and the output produced. However, in developing nations, especially those in the African context, there are many concerns over the quality of postgraduate students, as well as, the 
quality of graduate programmes. For instance, many studies have reported that low quality is seen of graduates from many universities in Nigeria and other African nations (Ansah et al., 2017; Boateng, 2014; Ibanga, 2015; Odigwe et al., 2018). In Nigeria particularly, universities, which should also be highly sought after, are gradually experiencing a decline in their enrolment rates (Agency Report, 2020) making it common to find graduates switching from one university to another for graduate programmes especially when opportunities from developed countries are presented. There also seem to be a decline in the quality of most postgraduate students churned out from the universities.

It was expected that students in graduate programmes develop effective skills in learning and research (Bassey \& Owan, 2018; Odigwe et al., 2020), yet many postgraduate students seem to lack such skills. It is also expected that lectures for graduate students in universities should be aided with computers and other sophisticated ICT gadgets to engage students and for effective teaching, research and records management purposes (Odigwe \& Owan, 2020). However, this does not also appear to be the case in most universities where many lecturers in graduate schools are found without basic ICT skills and are not making use of such tools (Abdulrazaq, 2016; Ejinkeonye \& Usoroh, 2016; Emeasoba \& Nweke, 2016; Maisamari, et al., 2018; Sani et al., 2016). Consequently, many are still utilizing such outdated, and ineffective approaches to teach and for supervising researches of graduate students.

The university systems tend to have failed in the promotion of research culture among graduate students. For instance, graduate programmes in a few Nigerian universities seem to have adopted global best practices by ensuring that all completed Masters and $\mathrm{PhD}$ researches are immediately published in the school's website without imposing any publication fees on the students. Thus, the research outputs of such universities are visible on search engines such as Google, Bing, Yahoo, and others. While many universities in Africa generally or Nigeria specifically, also have websites, the research output concluded by graduate students are not usually published in these websites. As a consequence, it is very rare or impossible to find full Theses or Dissertations of studies conducted by postgraduate students in such universities, unless such studies were uploaded by the students themselves in online repositories such as ResearchGate, Academia.edu, SSRN, bepress, and so on. If this situation persists, how can higher education achieve one of its core visions of promoting effective research and knowledge production?

Observations by the researchers led to the perception that the learning environments for graduate programmes in most universities, as earlier stated are unconducive. The incidence of unavailable lecture venues, inadequately equipped resource rooms, e-library, inadequate instructional facilities, intermittent power supply, deteriorating hostel facilities, noise pollution, and poor maintenance culture among others seems to be common and critical to affecting the smooth running of graduate programmes. The poor condition of service currently provided, has made many staff in graduate schools wished they were taken to other parts of the world for greener pastures. The poor conditions of service could be attributed to the weak financing of Nigeria's education sector. For example, in Nigeria, 7.025 per cent was allocated to education in the 2018 budget, notwithstanding the UNESCO's recommendation of a $26 \%$ budgetary allocation in developing nations for the education sector (Odigwe \& Owan, 2019). The poor trend continued, where Nigeria also committed 7.05 per cent and 6.7 per cent of its general budget for education in 2019 and 2020
(Ameh, \& Aluko, 2019; Amoo, 2019; Shuaib, 2019). Consequently, the pattern of education funding has been generally reported to be inadequate and below the 26\% suggested by UNESCO (Ekaette et al., 2019; Odigwe \& Owan, 2019; Oguche \& Haroun, 2017; Yusuf, 2020).

Although the poor funding trend by the government justifies the lack of many infrastructure and resources, it does not, however, provide adequate account or reasons why available facilities are not properly managed. For instance, Tertiary Education Trusts Fund (TETFUND) has been supporting schools with new buildings and other capitalintensive facilities. The e-libraries of universities are from time-to-time equipped with computers and other ICT gadgets to inject digital life into all the graduate students. Unfortunately, it appears all these efforts stated above, and many others not mentioned, are yielding fruitless results, and no valid proof exists to show as an improvement. These may be some of the reasons African universities are ranked so low in the world order of university ranking, which potentially affects sustainability in terms of enrolment because many prospective students check such metrics while making admission decisions.

This made the researchers wonder whether the problems identified above (which could potentially hinder the SGPs) have any relationship with the managerial activities of institutional leaders. Managerial processes are office activities which are important to sustain a working organisation. According to Grimsley (2018), administrative processes are a set or system of rules that govern the procedures for managing an organization to establish efficiency, consistency, responsibility, and accountability. Thus, it can be added that managerial processes refer to the systematic approaches adopted by administrators to manipulate, direct, control and coordinate all the activities of people and workflow within organizations to ensure that end purposes are attained. Managerial processes are important because they provide an objective set of rules by which an organization is governed; they help establish the legitimacy of management action by ensuring the application of management rules and decisions is done in an objective, fair, and consistent manner; and they also help ensure that managers are held accountable for decisions that deviate from the procedures (Grimsley, 2018). The scope of managerial processes is very wide; however, the focus of this study is on strategic planning, staff management, and information/communication management. The various aspects of this study are hereby discussed in the review of literature as follows.

\section{LITERATURE REVIEW}

\section{Strategic Planning}

The concept of strategic planning became prominent in corporations during the 1960s and remains an important aspect of strategic management (Simandan, 2018). Because of its potential to contribute to the growth and survival of educational institutions, strategic planning has steadily gained status as a management tool. It may act as a valuable framework for the SGPs. Strategic planning is described as an organizational management practice used to set targets, concentrate attention and resources, improve programs, ensure that staff and other stakeholders collaborate towards shared goals, agree on planned result(s), review and where possible, change the course of the organization in response to a changing environment (Balanced Scorecard Institute (BSI, 2018). It encompasses a set of concepts procedures and tools, designed to assist leaders and managers with their tasks (Bryson, 2018). 
Hence, strategic planning may support the implementation of a sustainability-oriented strategy and help drive organizational structure as it works towards sustainability goals. It establishes a focal point around the expected outcome or results. It assesses and adjusts accordingly, the institution's directions and react to changes within and outside the organization. It is a comprehensive statement of an organization's mission, objectives, and strategies and a detailed roadmap that an organization intends to follow in conducting its activities (Yepwi, 2007). It has become increasingly clear that to survive and thrive, organizations must make decisions that serve the interests of the environment and society. The study of Wanjala and Rarieya (2014) revealed that factors such as strategic planning experience and understanding, models of leadership, financial capital, training, and technical assistance have an impact on strategic planning; leadership is fundamental to the good functioning of strategic planning. Despite its importance, a study conducted by Abdulkareem et al, in 2011, revealed that in Nigerian universities, the level of implementation of the strategic plans was weak.

Comparably, Iso's (2016) research showed that strategic plan, archive, information and modern media services, post-UTME screening test, university portal and outsourced service had a major impact on the sustainability of universities. This is possibly one of the reasons why the research of Nwankwo et al., in 2015, earlier proposed that the end-users of university goods should be interested in strategic analysis and planning and that university management and strategic planning teams should be developed to enhance the capacity of university management. After examining the factors affecting the execution of strategic administration plans to chosen tertiary foundations in Meru Central District, Kenya, the study of the Messah (2014) Uncovered a poor impact of strategic analysis on managerial behaviour in the management and institutional policies; strategic planning was also found to be low due to the weak understanding and poor use of the system of services, which is a vital barometer of quality and efficacy of policy execution.

\section{Staff Management}

Staff management is the role of overseeing all personnel in the institution and improving the abilities of workers through training and other types of staff development, as well as defining, improving and implementing the training requirements and services available to staff (Ventureline.com, 2018). Staff includes permanent, temporary, and part-time employees, people employed on awards, mentorships, apprenticeships, and similar relationships. To Nnaji (2016), staff management is the care of employees' skills, knowledge, competencies, abilities, talents, and attitudes to conform to school standard and to achieve educational goals. It is the acquisition, maintenance, and utilization of human resources to influencing productivity, quality, and profitability in a bid to achieve sustainable development of the educational system (Akeke, 2016).

From the above, we define staff management as an aspect of personnel/human resource management that concerns taking practical steps towards ensuring that the right calibres of people are employed, retained, maintained and optimally utilized to attain stated organizational goals. In the university, the staff includes academic and non-academic as well as temporary, permanent and part-time staff. Crucial activities of staff management include "personnel planning, recruitment, selection, orientation, training, placement, job analysis, discipline, supervision, promotion and remuneration" (Agunwa et al.,
2019). Empirically, a study used staff training and provision of incentives as predictor variables and found a significant effect of these variables on the dependent variable (quality assurance) in a tertiary institution (Akeke \& Ofem, 2016). In a universal basic education report, it was found that the availability of support resources such as staff guidance/counselling services, staff development services, and ICT were substantially related to the achievement of universal basic education objectives, respectively (Owan, 2018).

The conclusion from the findings of a recent path analytic study conducted by Owan et al. (2020), revealed amongst others, that staff placement and motivation significantly predicted teachers' affective and continuance job commitment, but not normative job commitment; staff retraining led to staff attrition and was not a significant predictor of employee job commitment across the three dimensions; staff retraining only promoted teachers' job commitment when it was accompanied with right job placement and sufficient motivation; a substantial composite effect exists of the three predictors (staff placement, retraining and motivation) on the affective and continuance dimensions of job commitment, but not the normative. This misaligns with the results of Atanda (2016), which revealed among others, that staff recruitment, placement and motivation practices have no significant influence on the task performance of the staff of the ministry of education in Oyo state; no significant effect was recorded partially for each of the independent variables.

Similarly, the results of another study indicated that recruitment, promotion and prompt payment of salaries significantly influenced teachers' job performance in the study area (Ijov et al., 2016). In a recent study, Arop et al. (2020) studied the effect of eight school management practices on teachers' and students' effectiveness respectively. The results of the analysis revealed that school management practices such as principals' leadership techniques, conflict management, motivation of teachers, discipline of teachers, supervision of schools, maintenance of student records, discipline of students, efficient interaction greatly influenced the productivity of teachers and academic success of students. This finding corroborated the results of an earlier study conducted in 2019 by Owan et al., which showed similarly that supervisory and records management practices jointly accounted for $66.4 \%, 71 \%$ and $86.8 \%$ of the total variance in students' academic performance, teachers' job effectiveness and administrative effectiveness respectively; these variables (supervisory and records management practices) significantly influenced students' academic performance, teachers' job effectiveness and administrative effectiveness.

The results of another study which showed that administrators' leadership, communication and supervisory competencies significantly affected staff instructional delivery, attendance regularity, preparation and record-keeping (Owan \& Agunwa, 2019). Another study also clarified, that there is a significant composite effect of the predictor variables (teachers' training, placement and supervision) from a regression analysis on the response variable - teachers' attitude to work (Arop et al., 2019); with training being the strongest predictor, followed by placement and supervision in that order. The results of another study in higher education showed that three aspects of innovative management (data management, research ethics management and provision of research grants) jointly influenced the research effectiveness of staff to a significant extent (Bassey \& Owan, 2018). 


\section{Information and Communication Management}

Information and communication (IC) management is the systematic planning, implementing, monitoring, and revision of all information and the channels of communication within an organization, and between organizations (Wikipedia, 2018); it also includes the creation and dispersal of current and updated knowledge to all recipients connected to the organization. Aspects of information and communications management include developing corporate communication strategies, designing internal and external communications directives, and managing the flow of information, including online communication (Wikipedia, 2018). IC management could be utilized in student management, staff management, records management, decision-making system, information dissemination, and institutional delivery. It fosters teaching effectiveness thereby promoting sustainable development. IC management is essential in the present-day educational management and it is directed towards harmonization and result-orientation.

IC management could facilitate educational outcome in terms of the decision-making process, networking, data warehouse, and day-to-day running in the office (Udida, 2016). Facilities and gadgets such as computers, projectors, printers, scanners, cameras, tapes, radios, television, telecommunication, internet services, mobile communication, satellite, e-mails, electronic transfer, medical diagnosis, and e-learning enhance educational management. With the rapid technological advancement, university academic staff needs development programmes to stay abreast with modern trends. Educating personnel on the usage of IC such as email, eLearning, the Web, intranets, extranets and other integrated digital networks is one of the techniques geared towards SGPs. Effective management of IC can provide quality educational services to users updating them with current information on school management as well as delivering the same information to receivers on time. It will enhance the overall admission activities of graduate students by making it more accessible to far distance student in terms of admission inquiry, registration, enrolment, and monitoring.

Regarding the management of IC in records keeping, Noah et al. (2014) revealed that ICT usage in record preservation was low, the use of ICT in school administration enabled school boards to facilitate the proliferation of information, data management and processing with greater speed and precision. Similarly, the study of Nguigi (2012) revealed that $61 \%$ of the respondents indicated that ICT was used in school financial management, which led to the conclusion that ICT is used in different areas of management including financial management. Some challenges facing the effective management of IC in tertiary institutions were identified by a study to include inadequate of ICT facilities, the unpreparedness for the use of computer capabilities in school operations, ineffective use of computers, and lack of expertise (Ochard et al., 2015).

Regarding the application of ICT in students' management for sustainable development of school programmes, it was found by Augustine (2017) that ICT utilization in student's enrolment, decision making, information dissemination, record keeping, and monitoring significantly influenced the administrative effectiveness in handling correspondences, coordinating school activities and assigning responsibilities. It was also shown that ICT facilities were accessible and usable for continuous assessment recording, examination ranking, among others; however, there was an epileptic power supply and poor maintenance culture, which hindered the use of ICT; most school heads lack the initiative on how generated revenues internally to finance and maintain the school (Igbinoba, 2016)

It was also revealed by a study that ICT can be used in accessing results online, filling of student personal data and communication; however, it was also revealed that the major hindrance to ICT utilization was the failure to provide electricity (Oboegbulam \& Ochai, 2013). The perception of educators about the importance of ICT is shallow (Oko \& Michael). The results of Arop et al. (2018) showed that effective communication management prompted good employee relationship, work performance and the attainment of stated organizational goals in higher education. This relates to the findings of another study which showed that participative management practices in planning and decision-making have a significant effect on institutional goal attainment (Omorobi et al., 2020). Therefore, good plans and decisions cannot be made without communication and information flow.

\section{The Present Study}

Having examined previous literature on the various aspects of this study, it was discovered that several attempts have been made in related areas. In terms of other dependent variables, there appears to be a lack of empirical literature on strategic planning. Generally, the independent variables of this study (such as strategic planning, staff management and IC management) have been widely studied in association with other dependent variables (such as students' effectiveness, staff performance, organizational performance, goal attainment, among others). However, it was overserved that none of the cited studies had focused on the sustainability of schools nor graduate programmes specifically. To the best of the researchers' knowledge, the present study appears to be the first to examine the ties between managerial processes and the sustainability of graduate programmes. The present study also used a predictive multiple linear regression modelling approach for statistical analysis and inference.

\section{Theoretical Framework}

This study is grounded on the Administrative Theory, advanced by Henri Fayol in 1916. During the period of the industrial revolution, countries were undergoing massive growth and expansion, shifting production from homes to industries (van Vliet, 2009). This created the need for management to combine workers' productivity and raw materials efficiently to achieve stated goals. Scholars, therefore, came up with various theories to address this problem. In his book, 'General and Industrial Management' (1916), Fayol identified five key functional areas which include planning, organising commanding, controlling, coordinating.

Planning refers to the collection and systematic arrangement of tasks to be carried out to fulfil the objectives of the enterprise. Organizing refers to placing the organization's resources to profitably use. Commanding is the practice of directing and encouraging workers to control their actions to accomplish the organization's objectives. Controlling involves measuring the performance of the organization, comparing it with the set standards, identifying the deviations from the proposed plans and taking the necessary corrective actions to make sure activities align with the schedules. Coordination is the unification, incorporation and scheduling of the actions of the social groups to achieve consistency in behaviour in the pursuit of common goals. The theory was based on the 14 principles (division of work, authority and 
responsibility, discipline, unity of command, unity of direction, the subordination of individual interest, remuneration, centralization of decision-making authority, scalar chain, order, justice, continuity of workers service, effort, esprit de corps) which were advocated by Fayol as requirements necessary for the organization to reach set goals.

The implication of Fayol's theory to the present study suggest that Heads of the department must take into consideration the principles outlined to drive the organization towards goals realization. For this to become a reality, the school management as well coordinators of graduate programmes must plan, and recruit the required personnel to work in the school. Such new personnel must be appropriately placed to handle task based on their specialization and competence. The managers of the graduate programmes must also ensure that proper directions are provided to personnel assigned duties for proper guidance and workflow. Another crucial implication this theory has for this study is based on workers' remuneration. When the universities' management motivate the workers using monetary and non-monetary stimuli, it will foster contribution among the workforce and promote the effective discharge of duties. With the principle of equity, if rewards are accorded to staff without any form of bias, it will also impact on the way services will be rendered in the graduate school by staff leading to a sustained workflow and workforce. By further implication, the staff who are to instruct graduate students must be assigned specific leaders they must report to and must work collectively to as a team under the principle of "spirit the corps" with total commitment for the realization of goals. Also, for the programmes in graduate schools to be sustained, new ideas and innovations must be in place especially in a changing society. Thus, the same old procedures for doing things should be improved for development and sustenance.

\section{METHODS}

The method of quantitative research was implemented for the study with a focus on the correlational research design. The aim of using the correlational research approach was to investigate the degree to which variations in one or more variables correspond with other variations in one or more factors based on correlation coefficients. It is concerned with discovering or clarifying relationships among variables using the correlation coefficient. The design of correlational research was adopted since the research was planned to examine the strength and nature of the relationship that exists between Managerial Processes and the SGPs in universities. Based on this research design, this study sought specifically to:

i. examine the relationship between strategic planning and SGPs (in terms of availability of funds, availability of facilities, and supervision);

ii. test the connection between staff management and SGPs (in terms of availability of funds, availability of facilities, and supervision);

iii. determine the management of ICT and SGPs (in terms of availability of funds, availability of facilities, and supervision);

iv. predictively evaluate the composite effect of strategic planning, staff management and management of ICT on the SGPs (in terms of availability of funds, availability of facilities, and supervision) v. predictively evaluate the partial effects of strategic planning, staff management and management of ICT on the SGPs (in terms of availability of funds, availability of facilities, and supervision)

\section{Participants}

The research population consisted of 149 administrators at the University of Calabar and Cross River University of Technology. Deans and Head of Departments (HODs) constitute this population. This population is composed of 23 Deans and 126 HODs. A total of 114 respondents (Deans $=15$; HODs $=99$ ). were targeted at the University of Calabar, with 15 faculties and 99 departments at the time of writing. At the time of writing, the Cross River University of Technology had 8 departments and 27 departments, with a total of 35 respondents (Deans $=8$; HODs $=27$ ). Considering the manageable number of elements in the population, the researchers followed the census method to evaluate the 149 administrators across the entire population. According to Arop et al. (2018), "Census technique is used in cases where the population to be studied is small or manageable such that, all the elements in it could be studied entirely" (p. 42). This sampling technique was adopted because the number of Deans and departmental heads available in the University of Calabar and Cross River University of Technology is 149 which can be managed effectively without any need to sample.

\section{Instrument and Measures}

The instrument used for data collection was a questionnaire designed by the researchers and entitled: "Managerial Processes and the Sustainability of Graduate Programmes Questionnaire" (MPSGPQ). The MPSGPQ was structured into three sections. Section A elicited demographic parameters of the respondents; while Section B elicited responses on Managerial processes, and Section C elicited responses on the SGPs. All the items were arranged on the 4 points Likert-type scale ranging from Strongly Agree (4 points) to Strongly Disagree (1point). Reverse points scoring system was adopted for negatively worded items. The measures of primary concern in this study include managerial processes (with sub-aspects such as strategic planning, staff management, and management of IC) and the SGPs (operationalized into the availability of funds, funds and supervision).

To ensure the validity of the instruments used for the study, the questionnaire was presented to three psychometric experts in Test Measurement and Evaluation Unit, Department of Educational Foundations, University of Calabar, and Two Planning Experts in the Department of Educational Management, the University of Calabar for face and content validity. Each of these scholars independently gave their observations, items considered irrelevant were dropped while relevant ones were retained. Suggestions were made consequently which guided the researcher in preparing the final draft. Thereafter, the instrument was presented to the supervisor who also went through them carefully before approving for administration.

The reliability of the instrument was established using Cronbach alpha reliability technique. In achieving this, a pilot study was conducted using 50 departmental heads from University of Calabar and Cross River University of Technology. The HODs were randomly selected from both universities and were also part of the study sample. The respondents were given the questionnaire to complete and after some days later, the completed instruments were returned. The instruments were coded and analysed using Cronbach alpha reliability method which gave reliability coefficients that ranged from .71 to .91 
Table 1. Cronbach alpha reliability estimates for the instrument $(\mathrm{N}=50)$

\begin{tabular}{|c|c|c|c|c|}
\hline Variables & Items & $\overline{\mathbf{X}}$ & $\mathrm{SD}$ & $\alpha$ \\
\hline Strategic planning & 6 & 21.62 & 4.58 & .79 \\
\hline Staff management & 6 & 21.24 & 5.60 & .87 \\
\hline Management of IC & 6 & 20.32 & 4.2 & .71 \\
\hline Availability of fund & 6 & 19.88 & 3.56 & .64 \\
\hline Availability of facilities & 6 & 22.46 & 5.54 & .89 \\
\hline Supervision & 6 & 22.8 & 5.55 & .91 \\
\hline
\end{tabular}

Source: Fieldwork (2018)

which justifies the reliability of the items by being coherent internally in measuring what it was designed to measure. The complete reliability estimates of the instrument are presented in Table 1.

\section{Data Collection/Analysis Procedures}

In collecting data for the study, the researcher personally visited the University of Calabar and Cross River University of Technology with the questionnaires. With the aid of three research assistants who were briefed about the purpose and approach of the study, copies of the instruments were successfully administered to the targeted audience after obtaining prior permission/consent to administer/participate in the research. Upon completion, administered copies questionnaires were retrieved after two days from the respondents. The respondents were quite careful in safeguarding the completed instruments which made it possible for the researchers to retrieve all the administered copies without any loss. This represented a $100 \%$ rate of return from the administered copies of the instrument. Data were analysed using descriptive statistics such as mean and standard deviation; while inferential statistics such as Pearson Product Moment Correlation and Multiple Linear Regression analyses where applicable.

\section{Model Specification}

The models of this study are specified based on the general multiple linear regression equation is given as:

$$
Y^{\prime}=a+b_{1} X_{1}+b_{2} X_{2}+b_{3} X_{3} \ldots b_{n} X_{n}
$$

Where

$\mathrm{a}=$ The intercept (the value of $\mathrm{Y}$ when all predictor variables are equal to 0 )

$\mathrm{Y}^{\prime}=$ the predicted value of the dependent variable

$\mathrm{b}_{1}-\mathrm{b}_{\mathrm{n}}=$ Unstandardized regression weights

$\mathrm{X}_{1}-\mathrm{X}_{\mathrm{n}}=$ Predictor variables

From equation (1), we derive the standardised regression model of this study specified in general form as:

$$
\grave{\mathrm{Y}}=\beta_{1} X_{1}+\beta_{2} X_{2}+\beta_{3} X_{3}+e
$$

Where

$\grave{Y}=$ the predicted value of SGPs generally

$\beta_{1}-\beta_{3}=$ Standardized regression coefficients of the three predictor variables

$\mathrm{X}_{1}-\mathrm{X}_{3}=$ The three predictor variables

$\mathrm{e}=$ Error term

Note that the 'a' term in equation (1) has been removed in the standardised equation since

$$
a^{\prime}=\hat{\mu}_{y}{ }^{\prime}-b_{1}{ }^{\prime} \hat{\mu}_{x 1}{ }^{\prime}-b_{2}{ }^{\prime} \hat{\mu}_{x 2}{ }^{\prime}=0-0-0=0
$$

From equation (2), three standardised partial multiple linear regression equations for each of the sub-variables of the response variable were derived. Thus, there are three new equations for each sub-variable of the dependent variable as shown below:

$$
\begin{aligned}
& \text { ̀े } 1=\beta_{1} X_{1}+\beta_{2} X_{2}+\beta_{3} X_{3}+e \\
& \grave{Y} 2=\beta_{1} X_{1}+\beta_{2} X_{2}+\beta_{3} X_{3}+e \\
& \grave{Y} 3=\beta_{1} X_{1}+\beta_{2} X_{2}+\beta_{3} X_{3}+e
\end{aligned}
$$

Where

$\grave{Y}_{1}=$ Predicted value of SGPs in terms of availability of funds

$\grave{Y}_{2}=$ Predicted value of SGPs in terms of availability of facilities

$\grave{Y}_{3}=$ Predicted value of SGPs in terms of supervision

$\beta_{1}-\beta_{3}=$ Standardized regression coefficients of the three predictor variables

$\mathrm{X}_{1}-\mathrm{X}_{3}=$ The three predictor variables

$\mathrm{e}=$ error term

\section{RESULTS}

\section{Hypothesis 1}

Strategic planning has no significant relationship with the sustainability of graduate programmes (SGPs) in terms of availability of funds, availability of facilities, and supervision. The independent variable of this hypothesis is strategic planning while the dependent variable is the SGPs. As presented in Table 2, the results disclosed that the p-values obtained are all less than the alpha level of .05 at 147 degrees of freedom. This implies that a significant relationship exists between strategic planning and availability of funds $(r=.670, p<.05)$, availability of facilities $(\mathrm{r}=.693, \mathrm{p}<.05)$, and supervision $(\mathrm{r}=.676, \mathrm{p}<$ .05) respectively. The outcome in Table 2 also showed a strong association between strategic planning and SGPs in general $(\mathrm{r}=.750$, $\mathrm{p}<.05)$. With these results, the null presumption was dismissed while the alternative hypothesis which states that strategic planning has a significant relationship with the SGPs in terms of availability of funds, availability of facilities, and supervision was upheld.

\section{Hypothesis 2}

There is no significant relationship between staff management and sustainability of graduate programmes (SGPs) in terms of availability of funds, availability of facilities, and supervision. The results as presented in Table 3 revealed that the respective p-values for the availability of funds, availability of facilities, and supervision are below the .05 level of significance at 147 degrees. This indicates that there is a significant relationship between staff management and availability of funds $(\mathrm{r}=$ $.795, \mathrm{p}<.05)$, availability of facilities $(\mathrm{r}=.620, \mathrm{p}<.05)$, and supervision $(\mathrm{r}=8.18, \mathrm{p}<.05)$ respectively. Generally, the results in Table 3 also shows that there is a significant relationship between staff management and the SGPs generally $(\mathrm{r}=.823, \mathrm{p}<.05)$. Based on the available 
Table 2. Pearson product-moment correlation matrix of the relationship between Strategic Planning and the SGPs in terms of availability of funds, availability of facilities, and supervision $(\mathrm{N}=149)$

\begin{tabular}{|c|c|c|c|c|}
\hline Variables & Mean & SD & Cal r & p-value \\
\hline Strategic planning & 14.85 & 5.460 & 1 & $\ldots$ \\
\hline Availability of funds & 14.85 & 5.344 & $.670^{* *}$ & .000 \\
\hline Availability of facilities & 14.59 & 5.268 & $.693^{* * *}$ & .000 \\
\hline Supervision & 14.72 & 5.548 & $.676^{* * *}$ & .000 \\
\hline SGPs generally & 14.72 & 4.882 & $.750^{* * *}$ & .000 \\
\hline${ }^{* *}$ Significant at the .01 alpha level (two-tailed) & $\mathrm{df}=147$ & Crit $r=$ & .159 & \\
\hline
\end{tabular}

Table 3. Pearson product-moment correlation matrix of the relationship between Staff Management and the SGPs in terms of availability of funds, availability of facilities, and supervision $(\mathrm{N}=149)$

\begin{tabular}{|c|c|c|c|c|}
\hline Variables & Mean & SD & Cal r & p-value \\
\hline Staff management & 15.07 & 5.473 & 1 & $\ldots$ \\
\hline Availability of funds & 14.85 & 5.344 & $.795^{* * *}$ & .000 \\
\hline Availability of facilities & 14.59 & 5.268 & $.620^{* * *}$ & .000 \\
\hline Supervision & 14.72 & 5.548 & $.818^{* * *}$ & .000 \\
\hline SGPs generally & 14.72 & 4.882 & $.823^{* *}$ & .000 \\
\hline${ }^{* *}$ Significant at the .01 alpha level (two-tailed) & $\mathrm{df}=147$ & Crit $\mathrm{r}=$ & .159 & \\
\hline
\end{tabular}

Table 4. Pearson product-moment correlation matrix of the relationship between Management of Information and Communication Technology and the SGPs in terms of availability of funds, availability of facilities, and supervision ( $\mathrm{N}=149)$

\begin{tabular}{ccccc}
\hline Variables & Mean & CD & Cal r & p-value \\
\hline Management of IC & 14.75 & 5.386 & 1 & $.809^{* *}$ \\
\hline Availability of funds & 14.85 & 5.344 & .000 \\
\hline Availability of facilities & 14.59 & 5.268 & $.728^{* *}$ & .000 \\
\hline Supervision & 14.72 & 5.548 & $.771^{* * *}$ & .000 \\
\hline SGPs generally & 14.72 & 4.882 & $.849^{* * *}$ & .000 \\
\hline${ }^{* *}$ Significant at the .01 alpha level (two-tailed) & $\mathrm{df}=147$ & $\mathrm{Crit} \mathrm{r}=$ & .159 & \\
\hline
\end{tabular}

evidence, there were sufficient statistical reasons to reject the null and retain the alternative hypothesis. By implication, there is a significant relationship between staff management and SGPs in terms of availability of funds, availability of facilities, and supervision.

\section{Hypothesis 3}

There is no significant relationship between the management of IC and SGPs in terms of availability of funds, availability of facilities, and supervision. The results in Table 4 shows that the p-values for the availability of funds, availability of facilities, and supervision respectively. This result indicates that there is a statistically significant correlation between management of IC and availability of funds $(\mathrm{r}=$ $.809, \mathrm{p}<.05)$, availability of facilities $(\mathrm{r}=.728, \mathrm{p}<.05)$, and supervision $(\mathrm{r}=.771, \mathrm{p}<.05)$ respectively. The result in Table 4 also indicates that $\mathrm{p}$-value for the SGPs generally, is less than the .05 level of significance at 147 degrees of freedom, indicating that the relationship between management of IC and the SGPs generally is statistically significant $(\mathrm{r}=$ $.849, \mathrm{p}<.05)$. Based on these results presented in Table 4 , the null hypothesis is rejected while the alternate hypothesis is retained, implying that there is a significant relationship between management of IC and SGPs in terms of availability of funds, availability of facilities, and supervision.

\section{Hypothesis 4}

There is no significant composite prediction of strategic planning, staff management and management of IC of the SGPs in terms of availability of funds, availability of facilities, and supervision. The result which can be seen in Table 5 shows a significant composite effect of strategic planning, staff management and the management of IC on the sustainability of graduates programmes generally, $\mathrm{F}(3,145)=287.925$, $\mathrm{p}<.05$. The explanatory variables accounted for $85.3 \%$ of the total variance in the SGPs generally (Y), with $14.7 \%$ of the remaining variable attributed to other variables extraneous to the model. In the dimension of availability of funds $\left(\grave{Y}_{1}\right)$, the result showed a significant effect of strategic planning, staff management, and the management of IC on the SGPs, $F(3,145)=162.081, \mathrm{p}<.05$. The independent variables contributed $76.6 \%$ to the variance in the SGPs, with the remaining $23.4 \%$ possibly explained by other factors not included in the model.

Table 5 also revealed a statistically significant prediction of the three exogenous variables (strategic planning, staff management and IC management) on the endogenous variable (SGPs) in terms of the availability of facilities $\left(\grave{Y}_{2}\right), \mathrm{F}(3,145)=77.291, \mathrm{p}<.05$, explaining a total of $60.7 \%$ of the total variance, with the remaining $39.1 \%$ due to other factors not studied. In terms of supervision $\left(\grave{Y}_{3}\right)$, the result in Table 5 indicated that the three predictors had a significant effect on the sustainability of graduates programmes $\mathrm{F}(3,145)=157.716, \mathrm{p}<.05$, sharing $76.1 \%$ of the total variance in the dependent variable, with other factors (not included in the model) accounting for the remaining $23.9 \%$. Conclusively, based on the findings of this study, the null hypothesis was rejected while the alternate hypothesis was discarded. This implies that there is a significant composite prediction of strategic planning, staff management and management of IC of the SGPs generally, and specifically in terms of availability of funds, availability of facilities, and supervision. 
Table 5. One-way Analysis of variance of the regression analysis showing the effects of strategic planning, staff and IC management on the SGPs

\begin{tabular}{|c|c|c|c|c|c|c|c|}
\hline Model & Source & SS & df & MS & $\mathbf{F}$ & Sig. & $\mathbf{R}_{\text {adj }}$ \\
\hline \multirow{3}{*}{ Yे } & Regression & 3020.015 & 3 & 1006.672 & \multirow{3}{*}{287.925} & \multirow{3}{*}{$.000^{\mathrm{b}}$} & \multirow{3}{*}{.853} \\
\hline & Residual & 506.964 & 145 & 3.496 & & & \\
\hline & Total & 3526.978 & 148 & & & & \\
\hline \multirow{3}{*}{$\grave{Y}_{1}$} & Regression & 3255.844 & 3 & 1085.281 & \multirow{3}{*}{162.081} & \multirow{3}{*}{$.000^{\mathrm{b}}$} & \multirow{3}{*}{.766} \\
\hline & Residual & 970.907 & 145 & 6.696 & & & \\
\hline & Total & 4226.752 & 148 & & & & \\
\hline \multirow{3}{*}{$\grave{\mathrm{Y}}_{2}$} & Regression & 2527.480 & 3 & 842.493 & \multirow{3}{*}{77.291} & \multirow{3}{*}{$.000^{\mathrm{b}}$} & \multirow{3}{*}{.607} \\
\hline & Residual & 1580.547 & 145 & 10.900 & & & \\
\hline & Total & 4108.027 & 148 & & & & \\
\hline \multirow{3}{*}{$\grave{Y}_{3}$} & Regression & 3487.074 & 3 & 1162.358 & \multirow{3}{*}{157.716} & \multirow{3}{*}{$.000^{\mathrm{b}}$} & \multirow{3}{*}{.761} \\
\hline & Residual & 1068.644 & 145 & 7.370 & & & \\
\hline & Total & 4555.718 & 148 & & & & \\
\hline
\end{tabular}

Table 6. Partial coefficients of strategic planning, staff management and management of information and communication and their prediction of SGPs generally and specifically

\begin{tabular}{|c|c|c|c|c|c|c|}
\hline Model & Variables & B & SE & $\beta$ & $\mathbf{t}$ & Sig. \\
\hline \multirow{4}{*}{ Ỳ } & (Constant) & .713 & .504 & & 1.414 & .160 \\
\hline & Strategic planning & .204 & .039 & .228 & 5.189 & .000 \\
\hline & Staff management & .352 & .040 & .395 & 8.814 & .000 \\
\hline & Management of IC & .385 & .044 & .424 & 8.755 & .000 \\
\hline \multirow{3}{*}{$\grave{Y}_{1}$} & (Constant) & .471 & .698 & & .675 & .501 \\
\hline & Strategic planning & .122 & .054 & .125 & 2.242 & .026 \\
\hline & Management of IC & .433 & .061 & .436 & 7.117 & .000 \\
\hline \multirow{4}{*}{$\grave{Y}_{2}$} & (Constant) & 1.887 & .890 & & 2.120 & .036 \\
\hline & Strategic planning & .325 & .069 & .337 & 4.680 & .000 \\
\hline & Staff management & .134 & .071 & .139 & 1.901 & .059 \\
\hline & Management of IC & .397 & .078 & .406 & 5.117 & .000 \\
\hline \multirow{3}{*}{$\grave{Y}_{3}$} & (Constant) & -.220 & .732 & & -.300 & .765 \\
\hline & Staff management & .512 & .058 & .505 & 8.822 & .000 \\
\hline & Management of IC & .324 & .064 & .315 & 5.083 & .000 \\
\hline
\end{tabular}

\section{Hypothesis 5}

The partial prediction of strategic planning, staff management and management of IC of the SGPs (in terms of availability of funds, availability of facilities, and supervision) is not statistically significant. The result in Table 6 indicates that strategic planning, staff management and the management of IC are significant partial predictors of the SGPs generally (Y). A unit increase in the standard deviation of the practices of strategic planning, staff management and IC management respectively, will lead to a $0.228,0.395$, and 0.424 increase in the standard deviation of the sustainability of graduates' programme generally. Out of the three independent variables (IVs), IC management was the strongest predictor of the sustainability of graduates' programme generally, followed by staff management and strategic planning in that order.

For sustainability in terms of availability of funds $\left(\grave{Y}_{Y}\right)$, the result in Table 6 shows that there is a significant partial effect of strategic planning, staff management, and management of IC. A unit boost in the standard deviation of strategic planning, staff management, and IC management accordingly, will lead to a $0.125,0.420$, and 0.436 increase in the standard deviation of the SGPs in terms of availability of funds. Among the three IVs, IC management was the strongest predictor of SGPs in terms of availability of funds, followed by staff management and strategic planning in that order.
For SGPs in terms of availability of facilities $\left(\grave{Y}_{2}\right)$, the result in Table 6 shows that two IVs (strategic planning and IC management) partially predicted the dependent variable significantly; while staff management did not significantly predict the SGPs in terms of availability of facilities. However, a unit increase in the standard deviation of the execution of strategic planning, staff management, and management of IC will lead to a $0.337,0.139,0.406$ increase in the standard deviation of the SGPs in terms of availability of facilities respectively. Among the three IVs, management of IC was again the strongest, thereafter strategic planning and staff management in that permutation.

In terms of SGPs in the dimension of supervision $\left(\grave{Y}_{3}\right)$ the result in Table 6 reveals that strategic planning, staff management and the management of IC are significant predictors. More specifically, it was discovered that a unit increase in the standard deviation of the application of strategic planning, staff management and IC management will lead to a $0.163,0.505$ and 0.315 increase in the standard deviation of the SGPs in terms of supervision respectively. It was also revealed in Table 6 that staff management was the strongest predictor of the SGPs in terms of supervision. Staff management is followed by management of ICT then strategic planning in that order.

Based on these results in Table 6 and from equations (2) and (4-6) specified in the methods section, the following regression models of this study were fitted. 


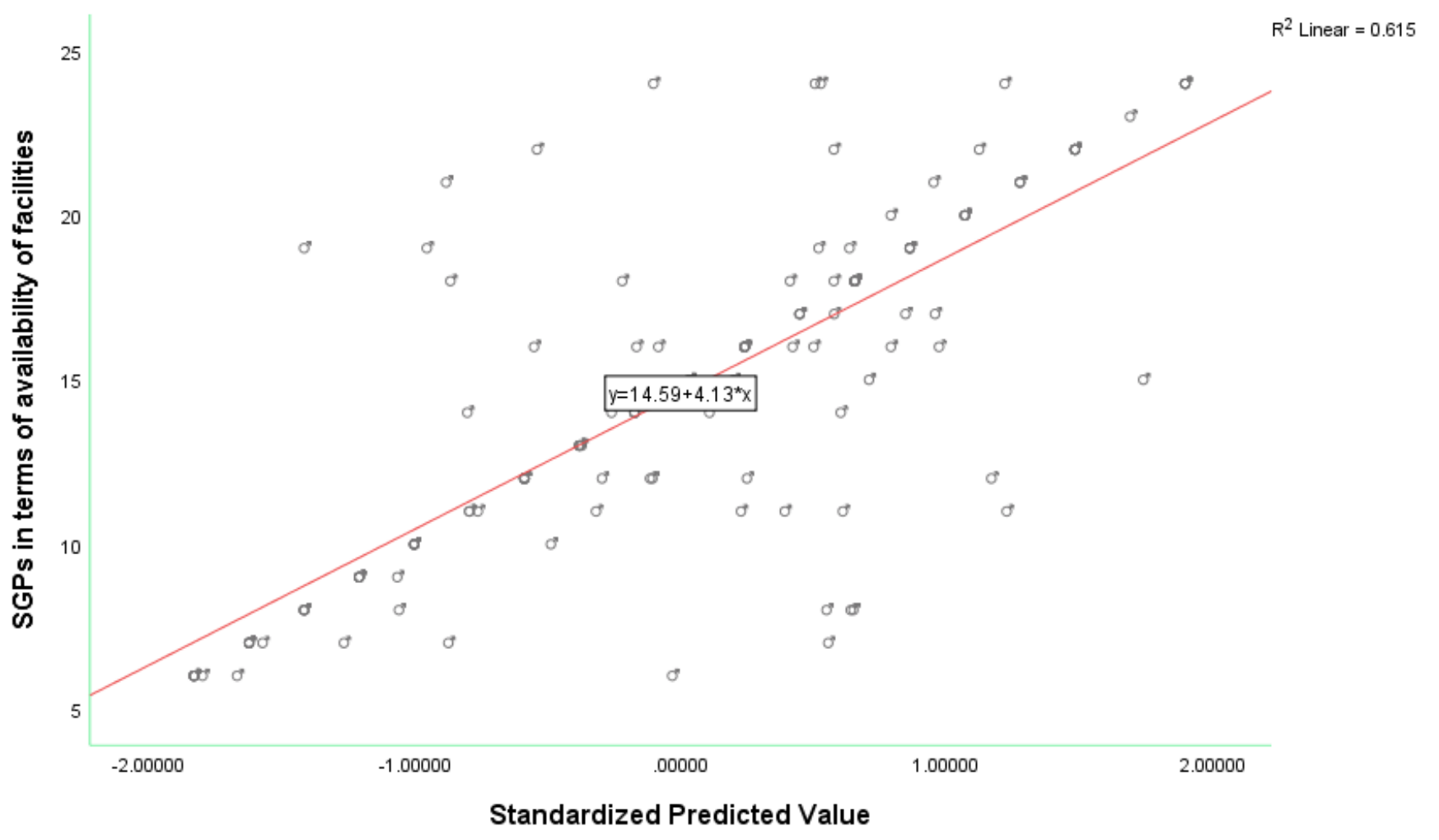

Figure 1. A standardised predictive model of the composite effect of strategic planning, staff and IC management on the SGPs generally

$$
\begin{aligned}
& S G P s_{\text {Gen }}=0.228 S P+0.395 S M+0.424 M I C+0.504 \\
& S G P s_{A f u}=0.125 S P+0.420 S M+0.436 M I C+0.698 \\
& S G P s_{A f a}=0.337 S P+0.139 S M+0.406 M I C+0.890 \\
& S G P s_{\text {Sup }}=0.163 S P+0.505 S M+0.315 M I C+0.732
\end{aligned}
$$

Where

SGPsGen $=$ Sustainability of graduate programmes generally

SGPSAfu $=$ Sustainability of graduate programmes in terms of availability of funds

SGPsAfa $=$ Sustainability of graduate programmes in terms of availability of facilities

SGPsSup = Sustainability of graduate programmes in terms of supervision

\author{
$\mathrm{SP}=$ Strategic planning \\ $\mathrm{SM}=$ Staff management \\ MIC $=$ Management of Information and Communication
}

From equations (7-10), we used the actual values of the measures to derive the standardized composite predicted values of each of the standardized multiple regression equations (7-10). Hence, the predicted models of each of the four multiple linear regression equations, as well as the line of best fit and the $\mathrm{R}^{2}$ are presented in Figures 1 to 4 .

\section{DISCUSSION OF FINDINGS}

Strategic Planning and the Sustainability of Graduate Programmes

The finding of this study showed that strategic planning has a significant effect on the sustainability of graduate programmes in terms of availability of funds, availability of facilities, and supervision. This finding by implication does not come as a surprise given that strategic planning is designed to fit the specific needs of the institution, to strengthen and enhance the performance and quality of the institution. Thus, all necessary actions that must be taken lieu with the smooth running of the graduate programmes must be carefully thought about in advance. This includes plans in terms of budget preparation, source of funds, taking records of worn-out facilities and making procurement for their replacement. If all these plans are adequately implemented, funds become available, facilities will be provided where they were missing with worn-out facilities removed from the system. Since plans on how to manage all the prospective resources have been earlier made, it goes a long way also strengthen the supervisory activities of the given room for the smooth running of the graduate programmes.

This finding agrees with the study of Iso (2016) which revealed that there was a significant influence of strategic plan, database, information and communication resources, post-UTME screening test, university portal and outsourced service on the sustainability of the university. Although the study of Iso did not focus specifically on the sustainability of graduate programmes, the implication of the finding is highly important to the present study which complements the generality of Iso's finding. The result of the present study corroborates the position of Nwankwo et al. (2015) stressing the need to engage the end-users of university products in strategic thinking and planning with the recommendation that university management and staff should receive 


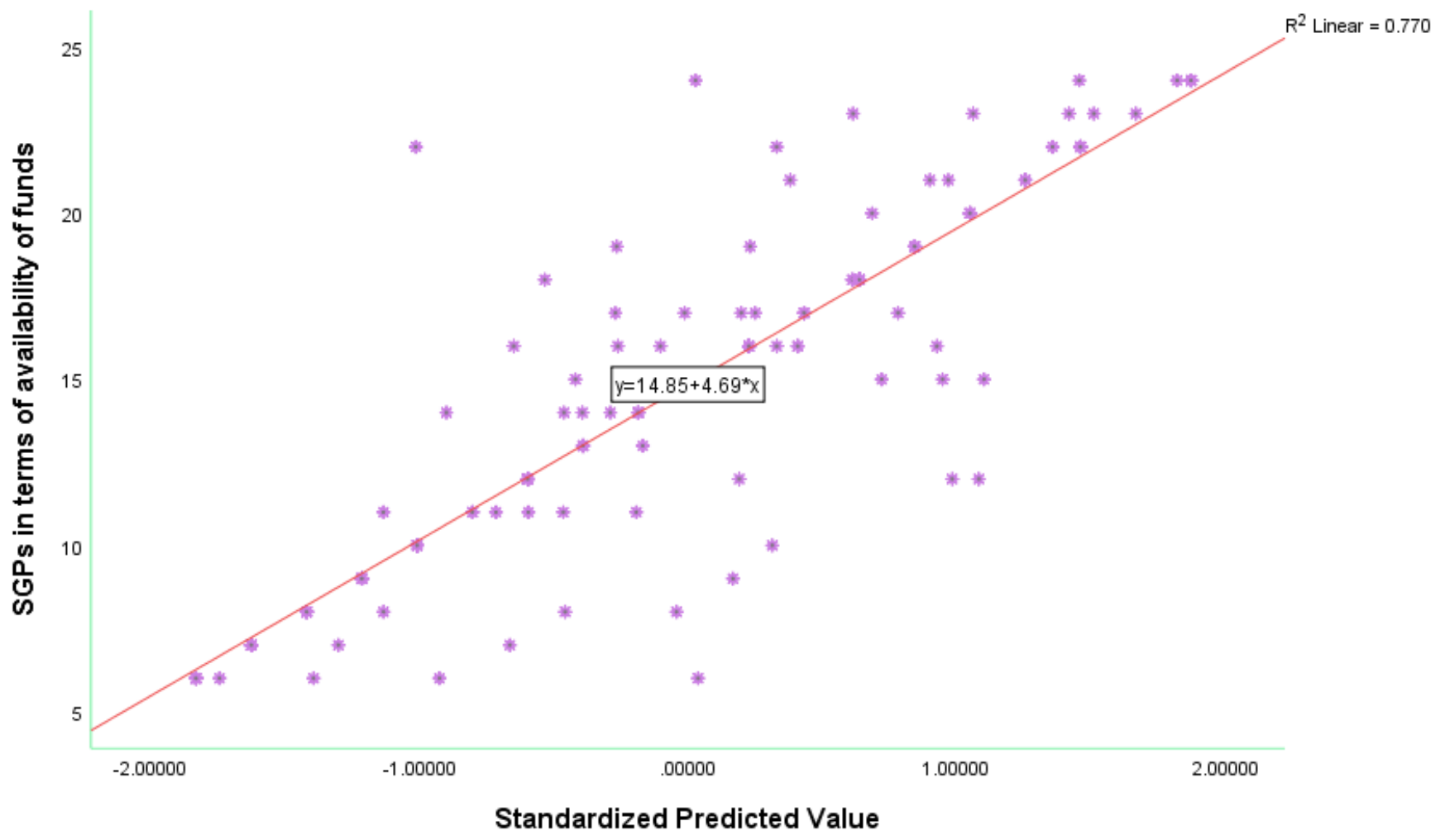

Figure 2. A standardised predictive model of the composite effect of strategic planning, staff and IC management on the SGPs in terms of availability of funds

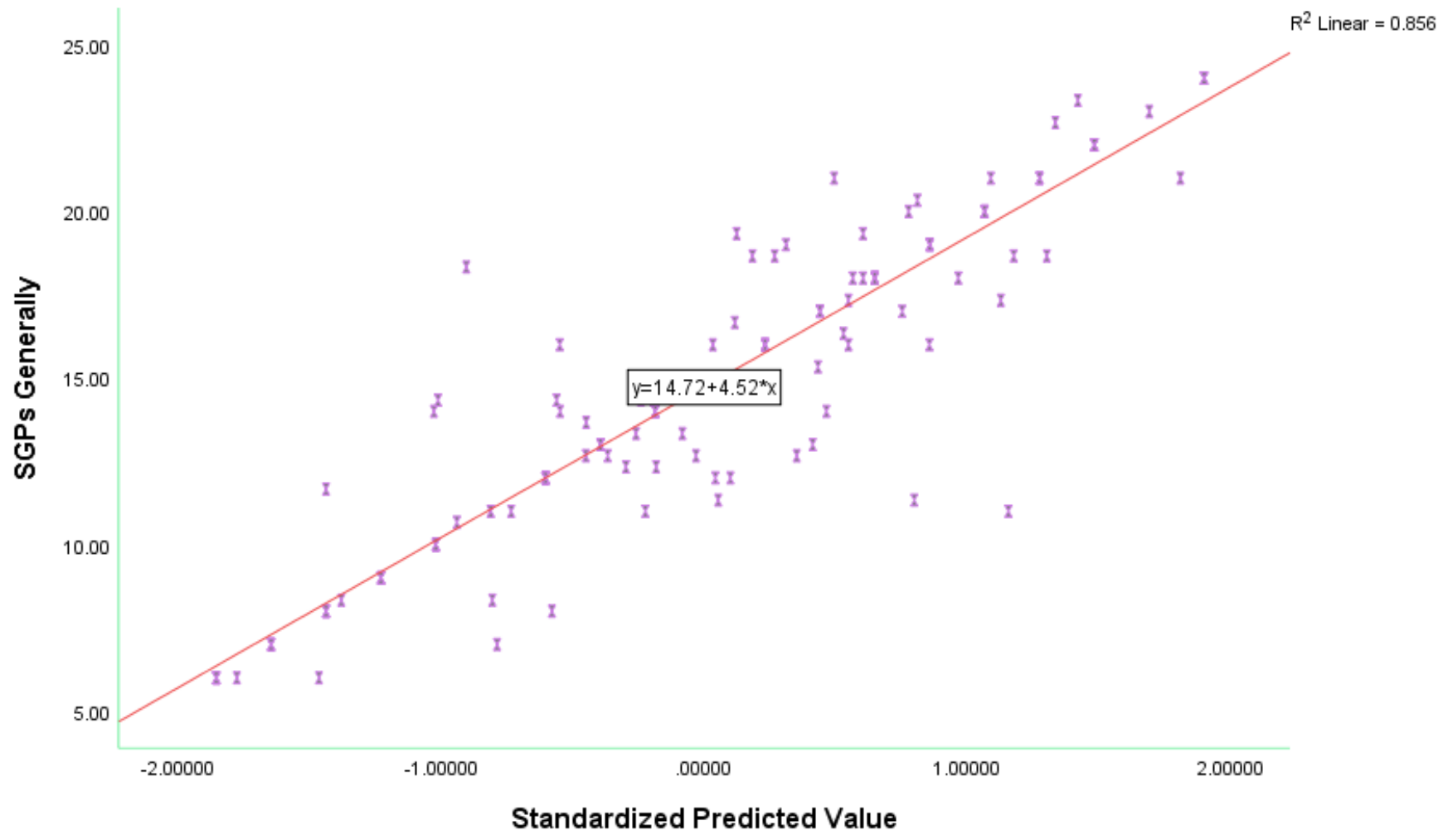

Figure 3. A standardised predictive model of the composite effect of strategic planning, staff and IC management on the SGPs in terms of availability of facilities 


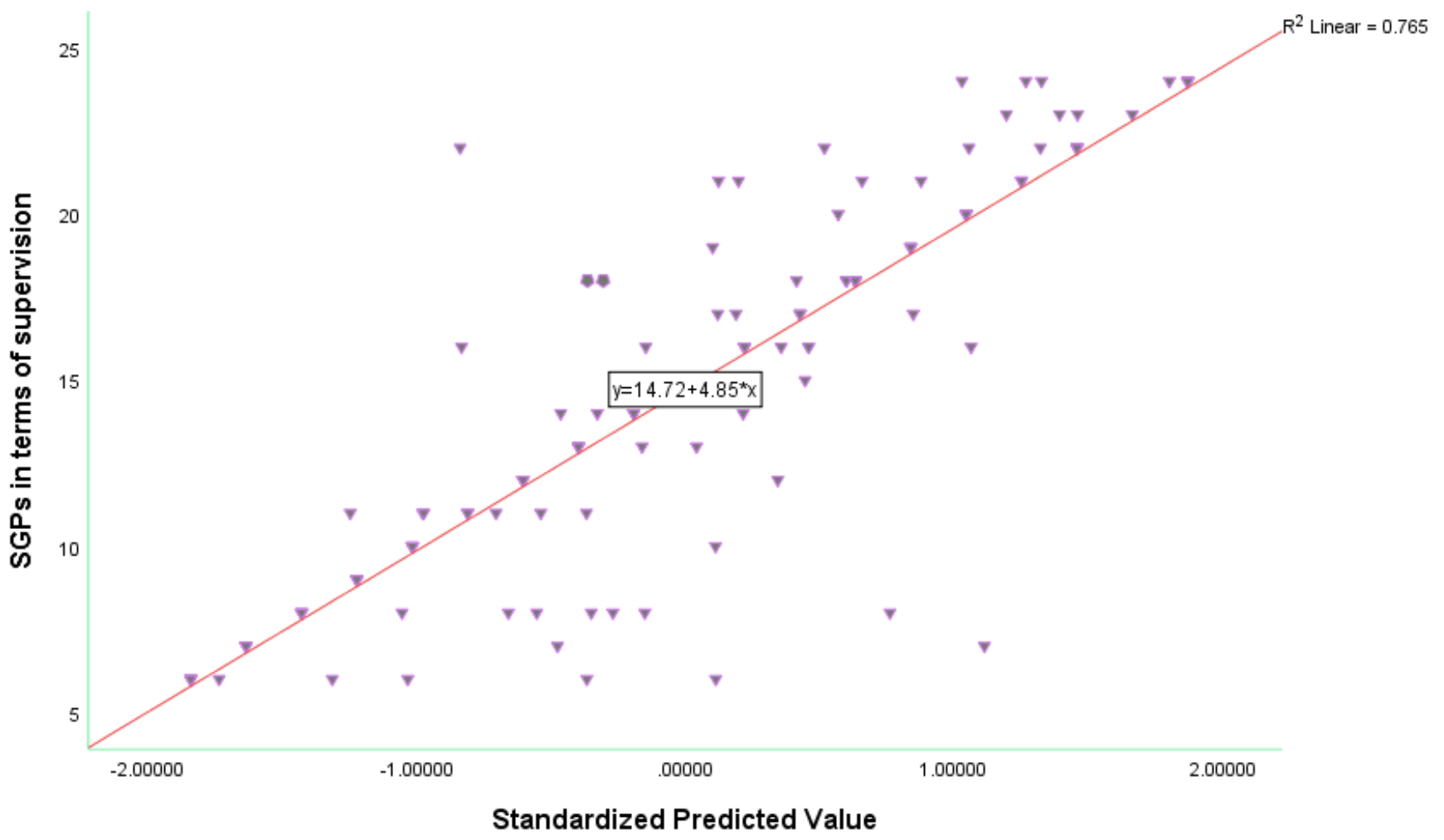

Figure 4. A standardised predictive model of the composite effect of strategic planning, staff and IC management on the SGPs in terms of supervision

training and orientation on strategic thinking receive training. Such training will enable the university managers to make crucial decisions in advance, that will enable graduate programmes to climb the sustainability ladder.

\section{Staff Management and the Sustainability of Graduate Programmes}

This study discovered through the second finding that there is a significant effect of staff management on the sustainability of graduate programmes in terms of availability of funds, availability of facilities, and supervision. This finding may be attributed to the dynamic role staff play in any school programme. Without staff, graduate programmes would not only be non-sustained, but there would also be no graduate programmes in the first place. Although the mere presence of staff is not enough to sustain graduate programmes, they must be properly placed, assigned task, guided accordingly, given the appropriate working conditions, motivated, supervised strictly and evaluated consistently to ensure they work in line with the programmes' goals and objectives. All these series of activities are what constitute staff management, and proper/consistent delivery of such administrative duties will promote the sustainability prospect of graduate programmes in universities.

This finding aligns with the findings of Akeke and Ofem (2016) which found a significant relationship between staff training and quality assurance in a tertiary institution and there is a significant relationship between the provision of incentives to staff and quality assurance in tertiary institutions. The study of Akeke and Ofem was considered as being related to this study because the sustainability of any graduate programme can be guaranteed when there is quality assurance in the university system. Therefore, if staff management (which includes training) is in place, the quality would be assured, and the chances of reaching the heights of sustainability will increase.

This finding also tallies with the results of many recent studies, which have shown that various management practices significantly relate to or affect different proxies of sustainability and job performance (Arop et al., 2019, 2020; Bassey \& Owan, 2018; Ijov et al., 2016; Owan et al., 2020; Owan \& Agunwa, 2019). The finding, however, disagrees with the results of Atanda (2016) that there is no significant influence of recruitment, placement and motivation practices on the task performance of staff. The disparity in the results is very obvious due to variations in the areas of study, nature of respondents, and year the studies were carried. It is also clear that this study's focus was on the sustainability of graduate programmes, and not on the task performance of ministry workers. Although the study of Atanda is related to this study, the dependent variables are different hence, the results.

\section{Management of IC and the Sustainability of Graduate Programmes}

It was also uncovered through the third finding that there is a significant relationship between the management of IC and sustainability of graduate programmes in terms of availability of funds, availability of facilities, and supervision. This finding implies that an improvement in the management of IC will improve the sustainability of graduate programmes generally and specifically in terms of availability of funds, availability of facilities, and supervision. This finding explains the important role that the management of information and communication play in graduate programmes. The significant relationship established in this study is not surprising because any graduate programme without adequate provision and management of information and communication is bound to fail. 
This supports the study of Augustine (2017) that ICT was utilized for student's enrolment, decision making, information dissemination, record keeping, and monitoring significantly influenced the administrative effectiveness in handling correspondences, coordinating school activities and assigning responsibilities. This means, in summary that ICT helps school administrator in school management. It can be seen from the findings of earlier scholars, the areas in which proper management of ICT will aid in the sustainability of graduate programmes. In line with the finding of this study, it can be said that the effective management of IC can provide quality educational services to users updating them with current information on school management as well as delivering the same information to receivers on time.

\section{CONCLUSION}

It was concluded generally that there is a significant nexus between managerial processes and the sustainability of graduate programmes in universities. Specific managerial processes such as strategic planning, staff management, management of IT significantly affects the sustainability of graduate programmes generally and specifically, in terms of availability of funds, availability of facilities, and supervision. Management of IC is the most influential managerial process that affects the sustainability of graduate programmes, followed by records management, staff management and strategic planning in that order. The management of graduate programmes has a role to play in ensuring that these processes of administration are adequately rendered to promote the sustainability likelihood of graduate programmes in universities. Based on the conclusion, the following recommendations were made:

i. Coordinators of graduate programmes should ensure that plans are made for the procurement and maintenance of facilities that will be required for the smooth running of the programmes in graduate schools.

ii. Non-governmental organisations, as well as philanthropist, should support the government in the funding of graduate programmes. This will provide ample opportunities that will aid the universities as well as graduate programmes' administrators to provide services as expected for the successful implementation of planned policies.

iii. Suitably qualified staff should be adequately recruited and placed into disciplines in the graduate programmes based on specialization and competence. Such staff should be adequately motivated (through the regular and consistent payment of salaries, promotion, and other incentives), supervised, and evaluated to trigger seriousness.

iv. The university management should provide adequate information and communication media and other related facilities to the graduate programmes to enhance effective teaching, research, and equip students with relevant ICT skills that will make them competitive in the dynamic society.

\section{REFERENCES}

Abdulkareem, A. Y., Akinnubi, O. P., \& Oyeniran, S. (2011). Strategic plan implementation and internal efficiency in Nigeria universities. European Science Journal, 8(3), 244-257. https://doi.org/10.19044/ esj.2012.v8n3p\%p

Abdulrazaq, B. A. (2016). Effective utilization of ICT for repositioning of library and information science education in tertiary institutions in Nigeria. European Journal of Basic and Applied Sciences, 3(2), 19-26. https://tinyurl.com/t7fp3kr

Agency Report (January 2020). Nigeria university enrolment 'near crisis with only 2 million students - NUC. https://bit.ly/33wJMX8

Agunwa, J. N., Owan, V. J., \& Ekpe, M. B. (2019). Personnel management: Implications for the effectiveness of the school system. International Journal of Research and Innovation in Social Science (IJRISS), 3(10), 391-395. https://tinyurl.com/wktu32q

Akeke, M. N. G. (2016). Management of school personnel: Academic staff. In C. C. Uchendu, \& B. A. Akuegwu (Eds), Educational management: A guide for practitioners (89-97). University of Calabar Press.

Akeke, M. N. G., \& Ofem, W. E. (2016). Human resource management techniques and quality assurance in tertiary institutions in Cross River State. International Journal of Educational Administration Planning and Research, 8(1), 7-15. https://bit.ly/3nhgmEj

Ameh, J., \& Aluko, O. (2019). 2019 budget: Education gets N620.5bn, against UNESCO's advice. The Punch Newspaper. https://bit.ly/36zglpw

Amoo, A. (2019). Nigeria allocates $6.7 \%$ of 2020 budget to the education ministry. https://bit.ly/3lqu6Lp

Ansah, F., Swanzy, P., \& Nudzor, H. P. (2017). Balancing the focus of quality assurance frameworks of higher education institutions in Africa: A Ghanaian context. In S. L. Renes (Ed), Global Voices in Higher Education. IntechOpen. https://doi.org/10.5772/ intechopen.68665

Arop, F. O., Mbon, U. F., Ekanem, E. E., Ukpabio, G. E., Uko, E. S., \& Okon, J. E. (2020). School management practices, teachers effectiveness, and students' academic performance in mathematics in secondary schools of Cross River State, Nigeria. Humanities and Social Sciences Letters, 8(3), 298-309. https://doi.org/10.18488/ journal.73.2020.83.298.309

Arop, F. O., Owan, V. J., \& Agunwa, J. N. (2019). Teaching personnel management and attitude to work in secondary schools of Calabar Education Zone of Cross River State, Nigeria. Prestige Journal of Education, 2(1),62-73.https://doi.org/10.11648/j.ijpbs.20190402.12

Arop, F. O., Owan, V. J., \& Ekpang, M. A. (2018). Effective communication management and the performance of tertiary institutions in Cross River State, Nigeria. International Journal of Current Research, 10(7), 72019-72023. https://goo.gl/opP4JW

Atanda, A. I. (2016). Influence of personnel management practice on task performance of Oyo State Ministry of Education Staff. International Journal of Educational Administration Planning and Research, 8(1), 90-104. https://bit.ly/2Sst2u0

Augustine, N. B. (2017). Information and Communication Technology utilization and Principals administrative effectiveness in public secondary schools in Calabar Education Zone of Cross River State (Unpublished Master's Thesis), University of Calabar, Nigeria. 
Ayeni, O. (2008). Private university system: The path to viable education in the new millennium. Spectrum Books Ltd.

Balanced Scorecard Institute (2018). Strategic planning basics. https://bit.ly/34oxuiX

Bassey, B. A., \& Owan, V. J. (2018). Innovation management and effectiveness of educational research in tertiary institutions in Cross River State, Nigeria. EPRA International Journal of Research and Development (IJRD), 3(13), 11-17. https://goo.gl/B1Nvjt

Boateng, J. K. (2014). Barriers to internal quality assurance in ghanaian private tertiary institutions. Research on Humanities and Social Sciences, 4(2), 1-9. https://bit.ly/3d1vSPK

Bryson, J. M. (2018). Strategic planning for public and non-profit organizations: A guide to strengthening and sustaining organizational achievement. John Wiley \& Sons. https://bit.ly/2GhrVLe

Clark, H. (2012). The importance of governance for sustainable development. Institute of Southeast Asian Studies, Singapore. https://doi.org/10.1355/9789814380447

Ejinkeonye, U. B., \& Usoroh, C. I. (2016). Enhancing the utilization of Information Communication Technology (ICT) among home economics lecturers in south-eastern Nigeria. Journal of Education and Practice, 7(9), 34-39. https://bit.ly/3ivGVlD

Ekaette, S. O., Owan, V. J., \& Agbo, D. I. (2019). External debts and the financing of education in Nigeria from 1988 - 2018: Implication for effective educational management. Journal of Educational Realities (JERA), 9(1), 1-14. https://bit.ly/366MJND

Emeasoba, C. N., \& Nweke, O. M. (2016). Level of availability and utilization of ICT facilities in teaching and learning of OTM in Polytechnics of South-Eastern States in Nigeria. Journal of Emerging Trends in Educational Research and Policy Studies (JETERAPS), 7(6), 404-413. https://tinyurl.com/sx9d3qf

Fayol, H. (1916). General and Industrial Management. Dunod et E. Pinat. https://doi.org/10.2307/258475

Garba, A. S. (2010). Refocusing education system towards entrepreneurship development in Nigeria: A tool for poverty eradication. European Journal of Social Sciences, 15(1), 140-165. https://bit.ly/30yeNYJ

Grimsley, S. (2018). What are administrative procedures? - Definition $\&$ explanation. https://bit.ly/33uJgsy

Ibanga, F. D. (2015). Solving the problem of poor quality of university graduates in Nigeria - A proposed holistic approach. British Journal of Education, 3(7), 52-70. https://bit.ly/2GCl7ri

Igbinoba, E. D. (2016). Use of ICT in students' record management in Ambrose Alli University, Ekpoma. Unpublished project, (Ambrose Alli University). https://bit.ly/2GpFZlL

Ijov, M. T., Hemen, M. T., Austin, A. O., \& Akinyemi, M. A. (2016). Human resource management and teachers' job performance in secondary schools in North West Senatorial District of Benue State, Nigeria. Journal of Teacher Perspective, 10(2), 1-14. https://bit.ly/3cYrCkc

Iso, E. U. (2016). Management of innovations and university system sustainability in South-South Nigeria (Unpublished PhD Thesis), University of Calabar, Nigeria.
Maisamari, A. M., Adikwu, V. O., Ogwuche, C. O., \& Ikwoche, F. (2018). Assessment of secondary school teachers' use of Information and Communication Technology (ICT) in Anyingba Metropolis, Kogi State, Nigeria. Journal of Education and Entrepreneurship, 5(1), 32-47. https://doi.org/10.26762/jee.2018. 40000010

Messah, O. B. (2014). Factors affecting the implementation of strategic plans in government tertiary institutions: A survey of selected technical training institutes. European Journal of Business and Management, 3(3), 85-105. https://bit.ly/33xRUqx

Nguigi, P. (2012). An investigation into the extent of use ICT in education management in public secondary schools in Naivasha District, Kenya (Master's Thesis), Kenyatta University, Kenya. http://irlibrary.ku.ac.ke/handle/123456789/6045

Nnaji, E. S. (2016). Management of school personnel: Non-teaching Staff. In C. C. Uchendu \& B. A. Akuegwu (Eds). Educational Management: A guide for practitioners (pp. 112-127). University of Calabar Press.

Noah, A. S., Akpabio, I. U., \& Sammy, M. E. (2014). Utilization of ICT for school record keeping: A strategy for principals' management of schools in Akwa Ibom State, Nigeria. Multidisciplinary Journal of Research Development, 22(1), 18-22. https://bit.ly/30PMTb9

Nwankwo, I. N., Omebe, C. A. \& Nwogbo, V. N. (2015). Towards revitalizing Nigerian university system through strategic thinking and planning. International Journal of Education, Learning and Development, 4(2), 10-20. https://bit.ly/3d02vO7

Oboegbulam, U. B., \& Ochai K. (2013). Application of ICT (Information and Communication Technology) in the Management of Universities in the North-Central State of Nigeria. US-China Education Review, 3(3), 187-194. https://bit.ly/3lenVtD

Ocharo, M. C., Nyakweba, I., \& Momanyi, G. (2015). The challenges facing computer implementation in administration in public secondary schools in Nyamira, North District, Kenya. International Journal of Novel Research in Education and Learning, 2(1), 14-29. https://bit.ly/36zgHfM

Odigwe, F. N., \& Owan, V. J. (2019). Trend analysis of the Nigerian budgetary allocation to the education sector from 2009 - 2018 with Reference to UNESCO'S 26\% Benchmark. International Journal of Educational Benchmark, 14(1), 1-14. https://bit.ly/2z5nZJA

Odigwe, F. N., \& Owan, V. J. (2020). Academic staff personal variables and utilization of ICT resources for research, teaching and records management in higher education. Proceedings of the 8th Annual European Conference on Education (ECE, 2020), 107-123. https://bit.ly/2GG36II

Odigwe, F. N., Bassey, B. A., \& Owan, V. J. (2020). Data management practices and educational research effectiveness of university lecturers in South-South Nigeria. Journal of Educational and Social Research, 10(3), 24-34. https://doi.org/10.36941/jesr-2020-0042

Odigwe, F. N., Offem, O. O., \& Owan, V. J. (2018). Vocational training duration and university graduates' job performance in Cross River State, Nigeria. International Journal of Current Research, 10(7), 7202472028. https://goo.gl/1m2R7x 
Oguche, M. S., \& Haroun, M. D. (2017). Exploring alternative sources of financing secondary schools in Nigeria for sustainable national development: A study of secondary schools in Kogi State Nigeria. American Based Research Journal, 6(4), 27-31. https://bit.ly/2StCexW

Oko, B. A., \& Michael M. F. (2016). ICT and quality of teachinglearning related activities in primary schools in Ogoja education zone of Cross River State, Nigeria. Global Journal of Educational Research, 15, 89 - 92. https://doi.org/10.4314/gjedr.v15i1.10

Omorobi, G. O., Mbon, U. F., Owan, V. J., \& Ekpenyong, J. A. (2020). Participative management practices and institutional goal attainment in Nigerian universities. American Journal of Social Sciences and Humanities, 5(1), 169-177. https://doi.org/10.20448/801.51.169.177

Owan, V. J. (2018). Management of educational support services and attainment of universal basic education goals in primary schools in Cross River State. Humanities and Social Sciences Letters, 6(4), 203210. https://doi.org/10.18488/journal.73.2018.64.203.210

Owan, V. J., \& Agunwa, J. N. (2019). Principals' administrative competence and teachers' work performance in secondary schools in Calabar Education Zone of Cross River State, Nigeria. Humanities and Social Sciences Letters, 7(1), 20-28. https://doi.org/10.18488/journal.73.2019.71.20.28

Owan, V. J., Arop, F. O., \& Agunwa, J. N. (2019). Path analysis of innovative management practices and secondary school system effectiveness in Cross River State, Nigeria. British Journal of Education, 7(3), 58-68. https://goo.gl/MVuyJX

Owan, V. J., Ekpe, M. B., \& Bassey, B. A. (2020). Staff placement, retraining and motivation as predictors of secondary educators' affective, continuance and normative job commitment: A path analytic study. Journal of the Social Sciences, 23(02), 551-563. http://www.apcjss.com/publication-show/2020/April/90/2825

Pisca, J. I. (2016). Management needs of departmental heads and the sustainability of academic programmes in Universities in Cross River State, Nigeria (Unpublished M.Ed. Thesis), University of Calabar, Nigeria.
Sani, Y. G., Kamaludeen, I. J., Abbas S. D., Abubakar A. A., \& Abdullahi, S. H. (2016). The use of Information and Communication Technology (ICT) by lecturers in North-Western Nigeria. Computer Engineering and Intelligent Systems, 7(8), 1-6. https://tinyurl.com/u2z7vpd

Shuaib, S. Y. (2019). SDG: 2020 Budget and education in Nigeria. Vanguard Newspaper. https://bit.ly/3itnnhD

Simandan, D. (2018). Iterative lagged asymmetric responses in strategic management and long-range planning. Time \& Society, 6(9), 34-42. https://doi.org/10.1177/0961463X17752652

Udida, U. J. (2016). Utilization of information and communication technology (ICT) in educational management. In C. C. Uchendu, \& B. A. Akuegwu (Eds). Educational management: A guide for practitioners (pp. 575-587). University of Calabar Press.

Van Vliet, V. (2009). 14 Principles of Management (Fayol). ToolsHero. https://bit.ly/34pWMgr

Wanjala, C. N., \& Rarieya, J.F.A. (2014). Strategic planning in schools in Kenya: Possibilities and challenges. International Studies in Educational Administration, 42(1), 17-30. http://hdl.handle.net/ 20.500.11910/1982

Wikipedia, the Free Encyclopedia (2018). Communications management. https://bit.ly/3ivIoIK

World Commission on Economic Development (1987). Our common future. Report of the World Commission on Environment and Development. https://bit.ly/36xdltB

Yepwi, B.A. (2007). Strategic planning procedure in the content of quality assurance at the school levels. In J. B. Babalola, G. O. Akpo, A. O. Ayeni, \& S. O. Adedeji (Eds), Access equity and quality in higher education. NAEP Publication.

Yusuf, H. O. (2020). Community support as an alternative and complementary source of funding basic education in Nigeria. European Journal of Education Studies, 6(12), 329-340. https://doi.org/10.5281/zenodo.3740244 